\title{
Apontamentos sobre as Cantigas de Santa Maria de D. Afonso X
}

Alex Rogério Silva

\section{Resumo}

Este artigo se propõe a apresentar a composição medieval intitulada Cantigas de Santa Maria, de autoria de D. Afonso X, rei de Leão e Castela. Tal obra foi empreendida em seu reinado (I252-I284), em concomitância com outros trabalhos de cunho científico e jurídico, influenciando a cultura do século XIII. D. Afonso X é tido como um mecenas do seu tempo, tendo adquirido o cognome de "O Sábio".

Palavras-chave: Cantigas de Santa Maria - D. Afonso X-Cantigas Medievais. 


\section{Notas sobre las Cantigas de Santa Maria de D. Afonso X}

Alex Rogério Silva

\section{Resumen}

Este artículo tiene como objetivo presentar la composición medieval titulada Cantigas de Santa María, cuyo autor es D. Alfonso X, rey de Castilla y León. Este trabajo se llevó a cabo durante su reinado (I252-I284), junto con otras obras de carácter científico y legal, que influyen en la cultura del siglo XIII. D. Alfonso X es considerado un mecenas de su época, adquiriendo el sobrenombre de "El Sabio".

Palabras-llave: Cantigas de Santa María - D. Alfonso X-Cantigas Medievales. 


\section{Introdução}

D. Afonso X, rei de Leão e Castela, é tido pelos historiadores como um grande incentivador da cultura na Península Ibérica no século XIII, um mecenas de sua época. Sob seu auspício ocorreu uma grande revolução cultural no Reino de Castela.

Sob seu mecenato foram impulsionados os conhecimentos de sua época em várias áreas do saber, recebendo em seu scriptórium ${ }^{\mathrm{I}}$, em Toledo, sábios e artistas de diferentes procedências e das três culturas então reinantes na Península Ibérica: a cristã, a judaica e a muçulmana.

A Afonso X creditam-se obras jurídicas, históricas, científicas ou pseudocientíficas, assim como obras sobre técnicas e lazeres, escritas em prosa castelhana. Mas também lhe são atribuídas obras literárias, ou melhor, poéticas, escritas em galego-português. Não admira, pois, que por toda parte se tenha atribuído a tão erudito monarca o cognome de "O Sábio", reconhecido no Ocidente europeu.

\section{As Cantigas de Santa Maria}

A obra poética mais conhecida de D. Afonso X são as Cantigas de Santa Maria, cujo foco principal é descrever as intervenções de santa Maria em relação aos atos pecaminosos dos homens.

Por meio dessas narrativas, além de louvar a Virgem, há o propósito de mostrar modelos moralizantes de conduta, um caráter "exemplar", apontando a opção pelo caminho cristão como o caminho do bem, o único caminho para a salvação.

Tal produção é tida como a "Bíblia estética do século XIII"”, por sua combinação entre os textos, música e miniaturas. $\mathrm{O}$ musicólogo catalão Higino Anglés considera que essa obra seja "o repertório musical mais importante da Europa no que se refere à lírica medieval" (ANGLÉS, I958).

I "Enorme escritório onde [o rei sábio] abrigava, sob o seu mecenato, poetas de todo o Ocidente românico, especialmente da Provença. Mas não só poetas; também desenhistas, miniaturistas, músicos e tradutores de várias origens, sem falar dos mestres em todas as artes liberais e também dos sábios de coisas do Oriente. Esse conjunto extraordinário de colaboradores do rei Afonso X, formados em três culturas diferentes - a muçulmana, a judaica e a cristã -, passou à história com o nome de Escola de Tradutores de Toledo”. LEÃO, Ângela Vaz. As Cantigas de Santa Maria. Extensão. Belo Horizonte, vol. 7, nº 3, ago. 1997, p. 27-42.

2 O termo foi um invento de M. Ménedez y Pelayo, primeiro em Las Cantigas del Rey Sábio, em La Ilustracion Española y Americana, nº 39, I985, e logo reimpresso em Obras completas. Estúdios y discursos de crítica históricay literatura, vol. I. Madri: CSIC, I94I, p. I6I-I89. 
Esse projeto, de acordo com Manuel Gonzaléz Jiménez, é:

[...] el resultado de uma compleja elaboración. Se admite que la obra se concibió inicialmente como un conjunto de 100 cantigas. A esta primeira coleccíon se añadieron otras 100 cantigas más, y se decidió entonces insertarlas em un códice ricamente miniado. Posteriormente, el número de cantigas se dobló, resultando al final unas 420 (GONZALÉZ JIMÉNEZ, 2004, p. 437).

O conjunto é formado por 420 cantigas, excluídas sete repetições, distribuídas em quatro manuscritos, escritas em galego-português, utilizando o ponto de partida versificatório para o exercício poético, o zéjel ${ }^{3}$. A maior parte delas constitui- se da narrativa, embora sem excluir o viés lírico, dos milagres da Virgem. Outra parte é composta exclusivamente por composições de louvor a Santa Maria.

Em traços gerais, as "cantigas de miragre" (cantigas de milagre) são composições que narram intervenções milagrosas da Virgem em favor dos seus devotos ou dos pecadores que a ela recorriam, e as "cantigas de loor" (cantigas de louvor) são verdadeiros hinos de louvor a santa Maria, em que há a exaltação das virtudes e beleza da Virgem.

Segundo Ângela Vaz Leão:

[...] o milagre é um acontecimento maravilhoso, com toques de fantástico, que se realiza em benefício de alguém, levando o seu beneficiário muitas vezes a conversão religiosa. Do ponto de vista literário, o milagre pode definir-se dentro dos gêneros medievais como uma narrativa curta, em que uma situação de crise se resolve pela intervenção de um santo, em favor de um beneficiário que, após receber a graça, faz muitas vezes o seu agradecimento num santuário dedicado àquele santo. $\mathrm{O}$ narrador costuma ser o próprio beneficiário, que faz o relato na primeira pessoa, como nas cantigas em que D. Afonso refere e agradece as curas de suas enfermidades; mas também pode ser uma testemunha do fato miraculoso, ou, ainda, um conhecedor que dele teve notícia por leitura ou por ouvir dizer (LEÃO, 2007, p. 24-25).

3 O zéjel é um tipo de composição poética medieval de origem moçárabe, ou hispano-muçulmana, teria sido criado por Mucáddam ben Muáfa, el Cabri, um poeta andaluz, natural de Cabra, região de Córdoba, entre o final do século IX e o início do século X. Compõe-se o zéjel, na sua forma canônica, dos seguintes elementos: a) Um refrão ou estribilho que, na maioria dos casos, é um dístico monorrimo e que, como é típico do refrão, se repete após cada estrofe; b) Um número variável de quadras, cujos três primeiros versos rimam entre si, mudando as rimas de estrofe para estrofe, e cujo quarto verso repete a rima do refrão (LEÃO, Ângela Vaz. Cantigas de Afonso X a Santa Maria (antologia, tradução e comentários). Belo Horizonte: Veredas \& Cenários, 20II, p. 27-28). 
[...] as cantigas de loor, que constituem a parte essencialmente lírica da coletânea. Algumas vezes em discurso direto, mostram sempre o Rei-trovador diante da Virgem Maria, exaltando-lhe as qualidades ou oferecendo-lhe a sua devoção, da mesma forma que, nas iluminuras respectivas, a figura do monarca é presença constante, na mesma postura humilde (LEÃO, 2007, p. 28).

Abaixo exemplifico uma cantiga de loor e de miragre com sua respectiva tradução para o português atual ${ }^{4}$ :

\section{II.I. Cantiga 10}

Esta é de loor de Santa María, com’ é fremosa e bõa e á gran poder.

Rósa das rósas e Fror das frores,

Dona das donas, Sennor das sennores ${ }^{5}$.

Rósa de beldad' e de parecer

e Fror d' alegría e de prazer,

Dona en mui pïadosa seer,

Sennor en toller coitas e doores.

Rósa das rósas e Fror das frores...

Atal Sennor dev' óme muit' amar, que de todo mal o póde guardar;

e póde-ll' os pecados perdõar, que faz no mundo per maos sabores.

Rósa das rósas e Fror das frores...

Devemo-la muit' amar e servir, ca punna de nos guardar de falir;

4 As respectivas traduções do galego português para o português atual foram retiradas da obra de LEÃO, Ângela Vaz. Cantigas de Afonso X a Santa Maria (antologia, tradução e comentários). Belo Horizonte: Veredas \& Cenários, 20II, p. 47 e I65.

5 A palavra Senhor usava-se para os dois gêneros no galego-português do século XIII. Nas cantigas afonsinas, era forma feminina, como se vê pelo artigo e pela contração das, no sintagma [a] senhor das senhores, no final do refrão. Traduziu-se por senhora no interior dos versos; porém, em final de verso, conservou-se a forma senhor, como feminina, para preservar a rima, o que ocorre na tradução desta cantiga. LEÃO, Ângela Vaz, 20II, op. cit., p. I67. 
des i dos érros nos faz repentir, que nós fazemos come pecadores. Rósa das rósas e Fror das frores...

Esta dona que tenno por Sennor

e de que quero seer trobador, se éu per ren póss' aver séu amor, dou ao démo os outros amores. Rósa das rósas e Fror das frores...

\section{II.II. Cantiga 10}

Esta é de louvor a Santa Maria e diz como é formosa e boa e tem grande poder

Rosa das rosas e Flor das flores,

Dona das donas "Senhor das senhores".

Rosa de beleza e bom parecer

E Flor de alegria e de prazer,

Dona em mui piedosa sempre ser,

Senhora em curar penas e dores.

Rosa das rosas e Flor das flores...

A tal Senhora deve o homem muito amar,

Pois de todo o mal o pode livrar

E os pecados lhe pode perdoar,

Que ele em vida faz, por maus pendores.

Rosa das rosas e Flor das flores...

Devemos amá-la muito e servir,

Pois se empenha em nos livrar de cair,

E pelos erros nos faz dor sentir,

Erros humanos, de pecadores

Rosa das rosas e Flor das flores...

Essa dona que tenho por Senhor

E de quem quero ser o trovador,

Se eu, por sorte, puder ter seu amor, 
Ao demo dou os outros amores.

Rosa das rosas e Flor das flores...

\section{II.III. Cantiga 381}

Como Santa María do Porto resuscitou un menino que morrera, fillo dun ome bõo que morava en Xerez.

Com' a voz de Jesú-Cristo faz aos mortos viver, assi fez a de sa Madre un morto vivo erger.

Desto direi un miragre que no Porto conteçeu que é de Santa María, dum menino que morreu, de Xerez, por que sa madre porên tal coita prendeu que a poucas a mesquinna ouvera d' ensandecer. Com' a voz de Jesú-Cristo faz aos mortos viver...

Seu padre deste meninno morava na colaçon de San Marcos, e Johane avía nom'; e enton de sa moller Deus lle déra aquele fillo baron, con que muito s' alegrava e prendia gran prazer. Com' a voz de Jesú-Cristo faz aos mortos viver...

Sancha sa madre chamavan per nome, com' aprendí, e amava aquel fillo atanto, segund' oý, que mais amar non podía outra ren; e foi assi que ben como llo Deus déra, assí llo ar foi toller. Com' a voz de Jesú-Cristo faz aos mortos viver...

Ca enfermou o meninno dũa gran fever mortal e o padre e a madre con coita del, non por al, levárono ao Pórto da Raynna espirital; e tẽendo-o a madre nos braços, lle foi morrer. Com' a voz de Jesú-Cristo faz aos mortos viver...

Sa madre, pois viu que mórto éra, ũa gran vóz déu dizend': “Ai, Santa María, dá-m' aqueste fillo meu; se non, leva-me con ele, ca mais non viverei eu 
eno mundo." E con coyta foi logo esmorecer.

Com' a vóz de Jesú-Cristo faz aos mórtos viver...

Da gran vóz que déu a madre quando a Virgen chamou,

Jesú-Cristo, o seu Fillo, aquel que resusçitou

Lázaro de quatro días e per nome o chamou,

fez levantar o menino tan tost' e vivo seer

Com' a vóz de Jesú-Cristo faz aos mórtos viver...

Mui são e muyt' alégre. E quantos eno logar

estavan e esto viron, começaron de chorar,

e en chorando a Virgen ar fillaron-ss' a loar

por tan fremoso miragre que fora alí fazer.

Com' a voz de Jesú-Cristo faz aos mortos viver...

\section{II.IV. Cantiga 381}

Como Santa Maria do Porto ressuscitou um menino que morrera, filho de um bom homem morador em Xerez.

Como a voz de Jesus Cristo aos mortos faz reviver,

Assim a de sua Mãe a um morto fez vivo se erguer.

Disso direi um milagre que um dia aconteceu

No Porto de Santa Maria, a um menino que morreu,

Natural de Xerez; por isso sua mãe tal dor sofreu

Que por pouco a pobrezinha escapou que ensandecer.

Como a voz de Jesus Cristo aos mortos faz reviver...

O pai desse menino na paróquia morava

De São Marcos e, por nome, João se chamava;

E, de sua mulher, aquele filho ao pai Deus confiava,

Dando-lhe com isso grande alegria e prazer.

Como a voz de Jesus Cristo aos mortos faz reviver...

Sancha era o nome que tinha a mãe, como aprendi,

E ela amava mais aquele filho, segundo ouvi,

Que a qualquer outra coisa amar mais podia; mas assim 
Como Deus lho dera, assim também lho veio receber.

Como a voz de Jesus Cristo aos mortos faz reviver...

Porque o menino adoecera de uma febre mortal,

E o pai e a mãe sofriam por ele de forma tal,

Que o levaram ao Porto da rainha espiritual;

Mas, tendo-o a mãe nos braços, aí lhe foi morrer.

Como a voz de Jesus Cristo aos mortos faz reviver...

A mãe, quando o viu assim morto, grande brado deu,

Dizendo: "Ai Santa Maria, dá-me este filho meu;

Se não, leva-me com ele, pois mais não viverei eu

Neste mundo." E de dor foi logo desfalecer.

Como a voz de Jesus Cristo aos mortos faz reviver...

Ao alto brado da mãe quando à Virgem apelou, Jesus Cristo, seu Filho, aquele que ressuscitou

Lázaro após quatro dias e pelo nome o chamou,

Fez prontamente levantar o menino e reviver.

Como a voz de Jesus Cristo aos mortos faz reviver...

Muito são e muito alegre. E quantos no lugar

Se achavam e isso viram, começaram a chorar;

E em chorando, se puseram a Virgem a louvar,

Pelo tão belo milagre que ali fora fazer.

Como a voz de Jesus Cristo aos mortos faz reviver...

E a título de ilustração, vejamos, por meio das figuras I e 2, como é a notação musical original de uma das CSM e como fica a sua respectiva transcrição para a notação musical atual feita por Anglés (I958).

As cantigas de milagre predominam sobre as de louvor, numa proporção de nove por um. Isto é: a cada grupo de nove cantigas de milagre segue-se uma cantiga de louvor, numerada com uma dezena inteira. No final da obra, porém, aparecem algumas cantigas de festas do calendário cristão, comemorativas de episódios da vida de santa Maria ou da de seu Filho. A estruturação das cantigas obedece, pois, a um ritmo regular, em que as cantigas de louvor ocupam sempre as dezenas, enquanto as de milagre têm números terminados pelas unidades de um a nove, comparando-se esse sistema, aproximadamente, ao de um rosário. 


\section{1.}

CANTIGA X, fol, $20 \mathrm{v}$ :

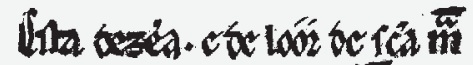

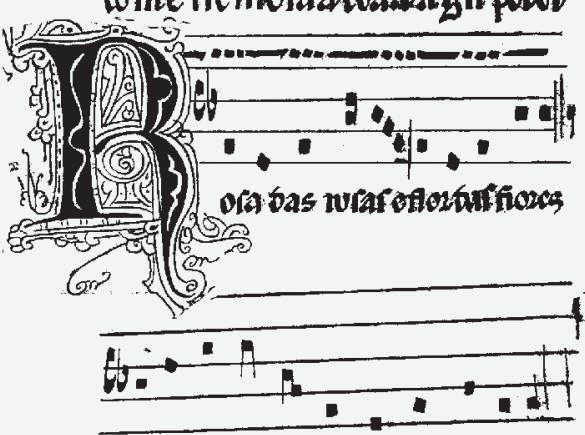

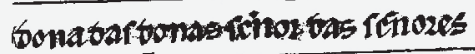
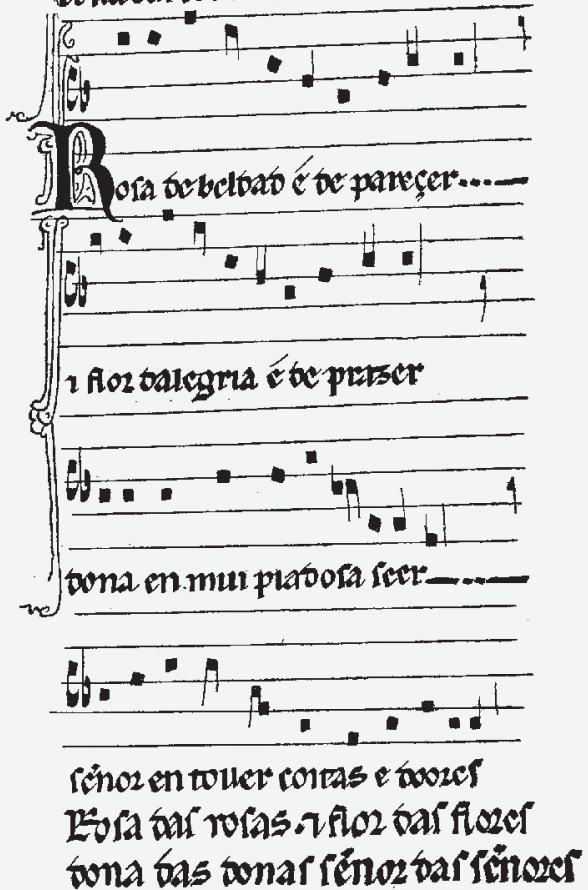

Figura I: Cantiga de Santa Maria no X - Rosa das rosas... - Fac-símile To. http://www.pbm.com/ lindahl/ cantigas/facsimiles/To/boborosmall.gif - acesso em 07/06/20I4. 
18

\section{0}

Esta é de loor de Santa Maria, com'é fremosa

et bõa, et á gran poder.

$$
\begin{array}{ll||l:l|ll}
A^{9} & A^{10} & b^{10} & b^{10} & b^{10} & a^{10} \\
\alpha & \beta
\end{array}\left|\begin{array}{c}
\gamma \\
\gamma
\end{array}\right|
$$
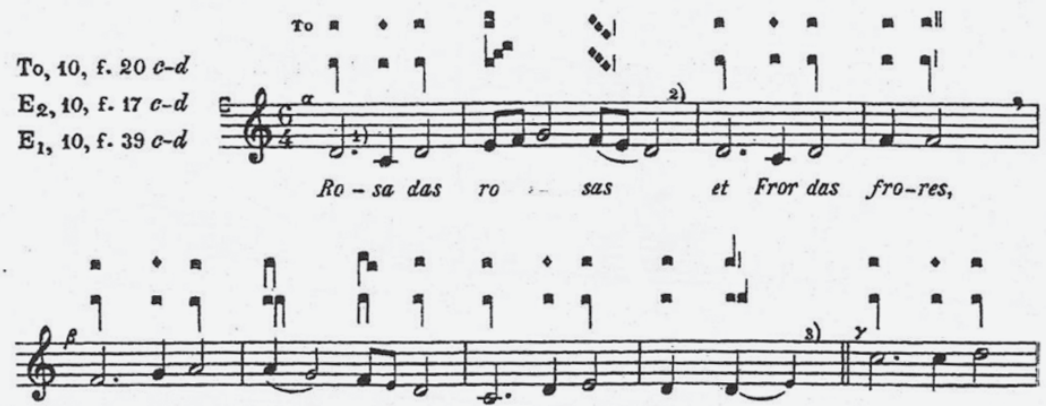

$$
\text { Do - na das do - nas, Se - nnor das se - nno-res. Ro - sa de }
$$
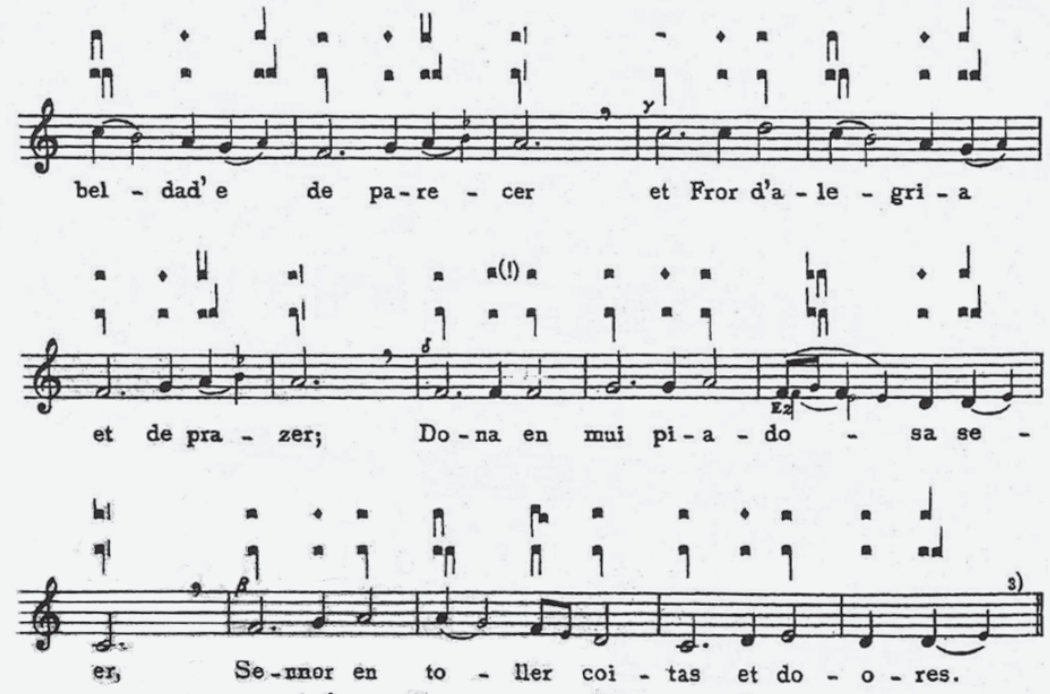

1) To ala ${ }^{\text {as superior. }}$ 2) To 0 3) To

Figura 2: Transcrição da GSM Io (ANGLÉS, I958, p. I8, "parte musical”). 
Sabe-se hoje que tal obra é uma compilação de fontes orais e escritas, incluindo-se aí experiências testemunhadas e vividas pelo rei. Sabe-se, também, que algumas das narrativas já apareceram em outros cancioneiros. Entre esses, são mais conhecidos: Los miragros de Nuestra Señora, de Gonçalo de Berceo ${ }^{6}$ e Les miracles de Nostre Dame, de Gautier de Coincy ${ }^{7}$. Por esse motivo, torna-se difícil afirmar com segurança a autoria de cada cantiga, embora alguns estudiosos afirmem ser possível descobrir, através de uma análise estilística, quais foram as cantigas elaboradas pelo próprio D. Afonso X.

\section{Os manuscritos}

O corpus dos manuscritos das Cantigas de Santa Maria compreende quatro manuscritos de extensão desigual escritos em galego-português, totalizando 427 cantigas que, descontadas sete repetições, se reduzem a 420 composições que estão guardadas hoje, dois na Biblioteca do Escorial, um na Biblioteca Nacional de Madri, mas proveniente de Toledo, e outro na Biblioteca Nacional de Florença.

Grê-se, entretanto, que um dos códices escurialenses e o códice florentino sejam dois volumes de um mesmo manuscrito, o que, se verdadeiro, reduziria os quatro testemunhos a apenas três ${ }^{8}$.

Os respectivos códigos são:

a. o de Madri, antigo de Toledo (códice To), com I26 cantigas;

b. um dos escurialenses (códice E), conhecido como "códice dos músicos", com 402 cantigas;

c. outro escurialense (códice $\mathrm{T}$ ), conhecido como "códice rico", graças às suas numerosas e belíssimas iluminuras, com 200 cantigas;

d. o florentino (códice F), que contém IO4 cantigas e, embora não acabado, complementa o anterior.

6 Gonçalo de Berceo viveu do século XII para o XIII (ignora-se a data exata de seu nascimento e de sua morte) e foi clérigo provavelmente do Mosteiro de San Millán, na região da Rioja, norte de Castela. Escreveu 25 poemas de milagres em castelhano arcaico, precedidos de uma introdução e reunidos na obra Milagros de Nuestra Señora (LEÃO, Ângela Vaz, op. cit., p. 36).

7 Gautier de Coincy viveu de II77 a I236 e foi prior da antiga Abadia de Saint-Médard, em Vic-sur-Aisme, burgo de Soissons, no nordeste da França. Compôs 60 poemas narrativos em francês antigo, reunidos sob o título de Les miracles de Nostre Dame (LEÃO, Ângela Vaz, op. cit., p. 36).

8 A hipótese dessa complementaridade foi formulada por Nella Aita na Revista de Língua Portuguesa. Rio de Janeiro, nº I3, I4, I5, I6 e I8 (de setembro de I921 a julho de I922). 


\section{As edições}

Além das antologias, quatro edições completas do texto se fizeram na era da imprensa até hoje. Uma delas foi publicada em dois volumes, em I889, por Leopoldo de Cueto, marquês de Valmar, sob encomenda da Real Academia Espanhola. Restringe-se aos textos e não leva em conta o manuscrito da $\mathrm{Bi}$ blioteca Nacional de Florença. Acha-se esgotada há muito tempo.

A outra foi objeto de edição crítica entre 1959 e I972 por Walter Mettmann, em quatro volumes, sendo três de textos e um quarto de glossário, sob os auspícios da Universidade de Coimbra. Com uma introdução em português, a edição tem por base o mais extenso dos manuscritos escurialenses, o códice $\mathrm{E}$, confrontado e complementado com os outros códices, dentro da boa técnica filológica. Essa edição já é rara, mas talvez ainda disponível no mercado de sebos. Com base na edição de Coimbra, publicou-se a edição galega de 198I, em dois volumes, pela Ediciós Xerais de Galicia, de Vigo.

Posteriormente, de I986 e I989, a mesma leitura de Walter Mettmann foi publicada, com revisões, pela Editorial Castalia de Madri, na coleção Clásicos Castalia. São três volumes, em formato de bolso, mas não em edição popular, sem o glossário, porém com introdução e notas em castelhano, pelo mesmo filólogo.

\section{v. Considerações finais}

A obra afonsina é muito ampla e está em diversas frentes, seja na literatura, nos estudos científicos, escritos jurídicos, tradução de obras, ou seja, foi desempenhado um alto trabalho em busca do conhecimento que resultou, como ficou registrado na história, em seu cognome de D. Afonso X, O Sábio.

Em especial, Cantigas de Santa Maria é uma obra tida como monumento do período medieval ibérico e nada mais desejo, com a escrita deste trabalho, do que despertar o interesse por essa obra tão importante - que goza de um reconhecimento universal, mas, algumas vezes, relegada ao silêncio nos países de língua portuguesa - e que possamos perceber o imaginário que os medievos nos legaram.

\section{Referências bibliográficas}

AFONSO X, O Sábio. Cantigas de Santa Maria, 4 vol. Edição crítica de Walter Mettmann. Coimbra: Acta Universitatis Conimbrigensis/Atlântida, I959-I972. 
ANGLÉS, H. La música de lãs Cantigas de Santa Maria del rey Alfonso El Sábio, vol. VIII-I. Barcelona: Diputación Provincial, I958.

GARRIÓN GUTIÉRREZ, José Miguel. Conociendo a Alfonso X El Sábio. Espanha: Imprenta Regional de Murcia, I997.

GONZÁLEZ JIMÉNEZ, Manuel. Alfonso X El Sábio. Barcelona: Ariel, 2004.

LEÃO, Ângela Vaz. Cantigas de Santa Maria de Afonso X, O Sábio. Aspectos culturais e literários. São Paulo: Veredas \& Cenários, 2007. . Novas leituras, novos caminhos: Cantigas de Santa Maria de Afonso X, O Sábio.

Belo Horizonte: Veredas \& Cenários, 2009.

- Cantigas de Afonso X a Santa Maria (antologia, tradução e comentários). Belo Horizonte: Veredas \& Cenários, $201 \mathrm{II}$.

MARTÍNEZ, Jesús Montoya \& RODRÍGUES, Ana Dominguez. El scriptorium alfonsí: de los libros de astrología a las Cantigas de Santa María. Madri: Editorial Complutense, I999.

Alex Rogério Silva - Graduado em História pela Universidade Estadual Paulista "Júlio de Mesquita Filho" em 20I4. Mestrando em História e Cultura Social pela Faculdade de Giências Humanas e Sociais (FCHS) da Universidade Estadual Paulista "Júlio de Mesquita Filho" (Unesp/Campus de Franca). 